\title{
Prevalence and risk factors for methicillin resistant Staphylococcus aureus carriage among emergency department workers and bacterial contamination on touch surfaces in Erciyes University Hospital, Kayseri, Turkey
}

\author{
Muge Oguzkaya-Artan ${ }^{1}$ Zeynep Baykan², Cem Artan ${ }^{3}$, Levent Avsarogullari ${ }^{4}$
}

1. Erciyes University Halil Bayraktar Health Services Vocational School, Kayseri, Turkey.

2. Erciyes University Medical Faculty Department of Medical Education, Kayseri, Turkey.

3. Kayseri Training and Research Hospital Department of Medical Microbiology, Kayseri, Turkey.

4. Erciyes University Medical Faculty Department of Emergency Medicine, Kayseri, Turkey.

\begin{abstract}
Objective: The aim of this study was to determine Staphylococcus aureus and methicillin-resistant S. aureus (MRSA) nasal carriage among emergency department (ED) workers, and bacterial contamination on hand-touch surfaces at ED.

Methods: This single-centered study enrolled 105 ED workers and 190 hand-touch surfaces at ED in June 2014. Nasal and environmental samples for $S$. aureus carriage and for bacterial contamination were obtained. For isolation swabs were cultured on ChromAgar $S$. aureus and environmental samples first cultured in broth and antibiogram obtained by clinical and Laboratory Standards Institute guidelines. A questionnaire was completed for each subject.

Results: The $S$. aureus carriage rate was $18.1 \%(\mathrm{n}=19)$, with $2.9 \%(\mathrm{n}=3)$ MRSA positivity. There were two (1.9\%) mobile phone positivities for $S$. aureus, one of them was MRSA, and a computer keyboard contamination for MRSA was also detected. All MRSA isolates were susceptible for the tested antibiotics. There was significant difference between gender $(p=0.044)$ in terms of nasal carriage of $S$. aureus and MRSA, all three MRSA isolates were from females.

Conclusion: Our study showed that the carriage of MRSA was not affected by clinical exposure in the hospital because of the existing infection control policy in our hospital.

Keywords: Staphylococcus aureus, carriage, risk factors, health care workers, bacterial contamination.

DOI: http://dx.doi.org/10.4314/ahs.v15i4.31

Cite as: Oguzkaya-Artan M, Baykan Z, Artan C, Avsarogullari L. Prevalence and risk factors for methicillin resistant Staphylococcus aureus carriage among emergency department workers and bacterial contamination on touch surfaces in Erciyes University Hospital, Kayseri, Turkey. Afri Health Sci. 2015;15(4):1289-94. http:// dx.doi.org/10.4314/abs.v15i4.31
\end{abstract}

\section{Introduction}

S. aureus is one of the most important human bacterial pathogens and methicillin-resistant $S$. aureus (MRSA) is currently the most commonly identified antibiotic resistant pathogen which is capable of causing a wide range of infections, especially through cross infection spread from patient to patient in hospitals and in oth-

\author{
Corresponding author: \\ Muge Oguzkaya-Artan, \\ Erciyes University, Halil Bayraktar \\ Health Services Vocational College, \\ Kayseri, Turkey \\ Tel: +903524375279 \\ Fax: +903524375936 \\ E-mail:martan38@gmail.com
}

er institutional settings. In contrast, healthy individuals have a small risk of contracting invasive infections caused by $S$. aureus. However, they can be carriers of the organism ${ }^{1,2}$. Infections caused by MRSA isolates are associated with longer hospital stay, prolonged antibiotic administration, and higher cost than infections caused by methicillin-susceptible $S$. aureus isolates. Next to colonized patients and contaminated environmental surfaces, colonized healthcare workers (HCWs) can act as a reservoir for the spread of MRSA to patients and other HCWs. Consequently, HCWs are frequently exposed to patients colonized with MRSA. Physical contact with patients and their environment is a known risk factor for MRSA acquisition. In general it's believed that HCWs are more likely to be colonized than persons in the general population, presumably because of increased exposure ${ }^{1-5}$. EDs may contribute to the spread of MRSA. Nurses, physicians, and ancillary staff care 
for multiple patients infected with MRSA during a single shift, increase the potential risk of spreading MRSA and other organisms from person to person with direct hand contact. Colonized HCWs and contaminated hand-touch surfaces are therefore potential risk factors for MRSA spreading in a busy $\mathrm{ED}^{6}$.

\section{Aims of the study \\ Determination of; \\ i. carriage rate of the $S$. aureus among ED workers, the risk factors and antibiotic susceptibilities \\ ii. MRSA contamination on hand-touch surfaces \\ iii. ED workers level of knowledge on the MRSA as an agent of hospital infection.}

\section{Materials and methods}

The study was a cross-sectional one, conducted on ED workers in Erciyes Medicine Hospital. It was supported by Erciyes University Scientific Research Project Unit. The study was planned in three sections: i.) S. aureus/ MRSA carriage rate, antibiotic resistance and risk factors among the ED workers. ii.) The carriage rate of S. aureus/MRSA on the mobile phones of ED workers and on different environmental samples iii.) the ED workers level of knowledge on the MRSA as an agent of hospital infection. In this article the nasal carriage of $S$. aureus, antibiotic susceptibilities and risk factors among ED workers; bacterial contamination on handtouch surfaces such as mobile phones, stethoscopes, desktop surfaces, telephones, keyboards, curtains, ultrasound probes, sinks, chairs, blood pressure cuffs in the ED were discussed.

The samples were collected in June $2014\left(2^{\text {nd }}, 3^{\text {rd }}\right.$, $9^{\text {th }}, 10^{\text {th }}, 16^{\text {th }}, 17^{\text {th }}, 23^{\text {rd }} 24^{\text {th }}$ of June 2014). We planned to take all the workers in day shift $(\mathrm{n}=111)$, and we reached 105 of them $(94.5 \%)$. The aim of this study was explained to the ED workers and all volunteers signed a consent form. The questionnaire elicited information on the followings: demographic characteristics (age, gender, profession, monthly income, smoking), risk factors for carriage (presence of chronic disease, antibiotic use in last one month, current use of antibiotics, hospitalization in past one year, number of persons in the same house, operation in last one year, living in the same house with another hospital staff).

Nasal swabs were obtained from the anterior nares of the volunteers. Samples were collected from both nares by rotating a sterile Stuart agar gel medium transport swab and sent to Erciyes University Halil Bayraktar Health Services Vocational School's Microbiology Laboratory (Kayseri, Turkey). The swabs were immediately streaked on CHROMagar S. aureus (Biolife, Italiana). After incubation for $24 \mathrm{~h}$ at $37^{\circ} \mathrm{C}$ suspected violent colonies were isolated and subcultured on to $5 \%$ sheep blood agar plates. The samples from environmental surfaces; mobile phones, stethoscopes, desktop surfaces, telephones, keyboards, curtains, ultrasound probes, sinks, chairs, blood pressure cuffs were cultured in brain hearth infusion broth enriched with $7.5 \% \mathrm{NaCl}$ for 48 $\mathrm{h}$ at $37^{\circ} \mathrm{C}$. Then subcultured to the ChromAgar S.aureus incubated for $24 \mathrm{~h}$ at $37^{\circ} \mathrm{C}$ and suspected violent colonies were isolated and subcultured on to $5 \%$ sheep blood agar plates.

The suspected colonies were confirmed to be $S$. aureus by standard biochemical techniques and conventional methods (colony morphology, Gram stain, catalase activity, tube coagulase test). Test for methicillin-resistance was performed by the Kirby-Bauer disc diffusion method, using cefoxitin (potency $30 \mu \mathrm{g}$ ) disc and ChromAgar MRSA. The other tested antimicrobial agents were: gentamicin $(10 \mu \mathrm{g})$, trimethoprim-sulfamethoxazole (TMP-SMX, 1.25/23.75 $\mu \mathrm{g}$ ), erythromycin (15 $\mu \mathrm{g})$, clindamycin $(2 \mu \mathrm{g})$, teicoplanin $(30 \mu \mathrm{g})$, vancomycin $(30$ $\mu \mathrm{g})$, rifampin $(30 \mu \mathrm{g})$ (all Bioanalyse, Turkey), on Muller Hinton agar with $24 \mathrm{~h}$ incubation at $35.8^{\circ} \mathrm{C}$. Results were interpreted according to the criteria of CLSI 2007 guidelines ${ }^{7}$. The reference strain S. aureus ATCC 29213 was used as internal quality control. The isolates positive for MRSA ( $n=3$ ) were tested by Phoenix (BD Diagnostic Systems, Sparks, MD) for both identification and antimicrobial susceptibilities.

This study was planned and performed in accordance with the Helsinki Declaration and was approved by the Ethics Committee of the Erciyes University Medical Faculty.

Statistical analysis: All data was expressed by numbers and frequencies. Chi-squared Fisher's exact test was used for comparison of categorical variables. A p value $<0.05$ indicated a statistically significant difference.

\section{Results}

The socio-demographic characterization of the ED workers was shown in Table 1. 
Table 1. The socio-demographic characteristics of ED workers enrolled.

\begin{tabular}{|l|c|c|}
\hline Characteristics & N & \% \\
\hline Age, years & & 14.3 \\
\hline$\leq 19$ & 15 & 57.1 \\
\hline $20-29$ & 60 & 22.9 \\
\hline $30-39$ & 24 & 5.7 \\
\hline$\geq 40$ & 6 & 41.9 \\
\hline Gender & 44 & 58.1 \\
\hline Male & 61 & 40.0 \\
\hline Female & & 13.3 \\
\hline Profession & 42 & 46.7 \\
\hline Physician & 14 & \\
\hline $\begin{array}{c}\text { Others (medical Secretary, } \\
\text { paramedics, cleaning staff) }\end{array}$ & 49 & \\
\hline
\end{tabular}

Out of 105 ED workers $57.1 \%$ were $20-29$ years of age and $58.1 \%$ were female. Nasal $S$. aureus carriage rate was $18.1 \%(n=19)$. Three workers were MRSA positive
$(2.9 \%)$. The distribution of possible risk factors was shown in Table 2. Gender was the only risk factor for the nasal $S$. aureus. Carriage rate among sexes was statistically different $(\mathrm{p}=0.044)$ (Table 2$)$.

Table 2. Distribution of risk factors among nasal $S$. aureus carriers.

\begin{tabular}{|c|c|c|c|c|c|c|}
\hline & \multicolumn{2}{|c|}{$\begin{array}{c}\text { S. aureus } \\
\text { Negative }(n=86)\end{array}$} & \multicolumn{2}{|c|}{$\begin{array}{c}\text { S. aureus } \\
\text { Positive }(n=19)\end{array}$} & \multirow[t]{2}{*}{$\begin{array}{c}\text { Chi } \\
\text { square } \\
\end{array}$} & \multirow[t]{2}{*}{$\mathbf{p}$} \\
\hline & $\mathrm{N}$ & $\%$ & $\mathrm{~N}$ & $\%$ & & \\
\hline \multicolumn{7}{|l|}{ Age groups } \\
\hline$<30$ & 63 & 84.0 & 12 & 16.0 & & \\
\hline$>30$ & 23 & 76.7 & 7 & 23.3 & Fisher & 0.407 \\
\hline \multicolumn{7}{|l|}{ Gender } \\
\hline Male & 32 & 72.7 & 12 & 27.3 & & \\
\hline Female & 54 & 88.5 & 7 & 11.5 & Fisher & 0.044 \\
\hline \multicolumn{7}{|l|}{ Profession } \\
\hline Physician & 32 & 76.2 & 10 & 23.8 & & \\
\hline Nurse & 14 & 100.0 & - & - & & \\
\hline Others & 40 & 81.6 & 9 & 18.4 & 4.021 & 0.134 \\
\hline \multicolumn{7}{|c|}{ Chronic diseases } \\
\hline No & 82 & 82.8 & 17 & 17.2 & & \\
\hline Yes & 4 & 66.7 & 2 & 33.3 & Fisher & 0.297 \\
\hline \multicolumn{7}{|c|}{$\begin{array}{lll}\text { Antibiotic } & \text { use } & \text { past } \\
\text { one month }\end{array}$} \\
\hline Yes & 12 & 85.7 & 2 & 14.3 & & \\
\hline No & $4 \overline{7}$ & 81.3 & 17 & 18.7 & Fisher & 1.000 \\
\hline \multicolumn{7}{|c|}{ Recent antibiotic use } \\
\hline Yes & 7 & 100.0 & - & - & & \\
\hline No & 79 & 80.6 & 19 & 19.4 & Fisher & 0.346 \\
\hline \multicolumn{7}{|c|}{$\begin{array}{l}\text { Hospitalization past } \\
\text { one year }\end{array}$} \\
\hline Yes & 3 & 75.0 & 1 & 25.0 & & \\
\hline No & 83 & 82.2 & 18 & 17.8 & Fisher & 0.566 \\
\hline \multicolumn{7}{|c|}{ Number of people } \\
\hline$<4$ & 43 & 79.6 & 11 & 20.4 & & \\
\hline$\geq 4$ & 43 & 84.3 & 8 & 15.7 & Fisher & 0.616 \\
\hline \multirow{2}{*}{\multicolumn{7}{|c|}{$\begin{array}{l}\text { Another person in } \\
\text { the same house }\end{array}$}} \\
\hline \multirow{2}{*}{\multicolumn{7}{|c|}{$\begin{array}{l}\text { the same house } \\
\text { Works in the hospital }\end{array}$}} \\
\hline & & & & & & \\
\hline Yes & 34 & 81.0 & 8 & 19.0 & & \\
\hline No & 52 & 82.5 & 11 & 17.5 & Fisher & 1.000 \\
\hline \multicolumn{7}{|l|}{ Smoke } \\
\hline Yes & 18 & 75.0 & 6 & 25.0 & & \\
\hline No & 68 & 84.0 & 13 & 16.0 & Fisher & 0.368 \\
\hline \multicolumn{7}{|c|}{$\begin{array}{l}\text { Another } \\
\text { smokes at the house } \\
\text { smoken }\end{array}$} \\
\hline Yes & 28 & 84.8 & 5 & 15.2 & & \\
\hline No & 58 & 80.6 & 14 & 19.4 & Fisher & 0.784 \\
\hline \multicolumn{7}{|c|}{ Monthly income } \\
\hline$\leq 3000 \mathrm{YTL}$ & 57 & 80.3 & 14 & 19.7 & & \\
\hline$\geq 3001$ YTL & 29 & 85.3 & 5 & 14.7 & Fisher & 0.599 \\
\hline
\end{tabular}


The only antibiotic resistance was to cefoxitin, two out of 19. All the MRSA isolates were susceptible for the antibiotics tested (gentamicin, TMP-SMX, erythromycin, clindamycin, teicoplanin, vancomycin, rifampin).
S. aureus was isolated from $1.9 \%$ of the tested mobile phones, (2 out of 105). One phone and one of the 14 keyboards were MRSA positive. S. aureus/MRSA was not isolated from the other environmental surfaces tested (Table 3).

Table 3. The samples taken from ED.

\begin{tabular}{lcc}
\hline Samples & N & S. aureus isolated \\
\hline Mobile phones & 105 & 2 \\
Stethoscope & 17 & - \\
Keyboard & 14 & 1 \\
Phone & 7 & - \\
Wheeled bed & 15 & - \\
Chair & 9 & - \\
Ultrasound probes & 2 & - \\
Blood pressure cuffs & 5 & - \\
Curtains between patients & 5 & - \\
Faucet & 3 & - \\
Basin interior & 3 & - \\
Desktop surface & 5 & -
\end{tabular}

\section{Discussion}

Nasal colonization with $S$. aureus and MRSA can precede infection in patients and contacts. Although general population $S$. aureus/MRSA rates are well described, the prevalence of $S$. aureus and MRSA nasal colonization in ED HCWs is not defined ${ }^{8}$. We aimed to determine the prevalence of $S$. aureus and MRSA nasal carriage among ED HCWs without evidence of an active site of staphylococcal infection and to identify the variables associated with carriage. We found a carriage rate of 18.1\% for $S$. aureus and $2.9 \%$ for MRSA among ED workers. There were also two studies done by the same research- ers in military hospital staff and chest hospital workers from our region (Kayseri, Middle Anatolia). The rates for $S$. aureus carriage were $13.2 \%$ and $15 \%$ respectively. MRSA carriage rate was $5.4 \%$ (one strain) in the first study and no MRSA was detected in the second ${ }^{9,10}$. A study from another city in Turkey, found $13.8 \% S$. aureus carriage and $1.8 \%$ MRSA in a state hospital staff ${ }^{11}$. These carriage rates are similar to ours. The isolates from these studies were resistant to some antibiotics in different rates but in our study including MRSA isolates were all susceptible to the tested antibiotics. From the world there are many studies ${ }^{2,3,12-14}$ (Table 4).

Table 4. Studies and prevalence of $S$. aureus and MRSA around the world.

\begin{tabular}{|c|c|c|c|c|}
\hline Country & Study year & Study population & \multicolumn{2}{|c|}{ Prevalence for \% } \\
\hline & & & S. aureus & MRSA \\
\hline USA (12) & 2010 & HCWs & 43.8 & 6.6 \\
\hline Saudi Arabia (3) & 2014 & HCWs & - & 73 \\
\hline $\operatorname{Iran}(13)$ & 2009 & $\begin{array}{l}\text { Surgical ward and } \\
\text { ED workers }\end{array}$ & 25.7 & 5.3 \\
\hline Ethiopia (2) & 2013 & $\begin{array}{l}\text { Nurses and other } \\
\text { HCWs }\end{array}$ & 28.8 & $\begin{array}{l}12.7 \text { and } \\
\text { in nurses } \\
21.2\end{array}$ \\
\hline India (1) & 2013 & Nurses & 17.5 & 14.3 \\
\hline Sri Lanka (14) & 2014 & Nurses & 39.4 & 13.3 \\
\hline
\end{tabular}


Albrich et al. ${ }^{5}$ provided data from 41 studies which studied HCWs carriage rates for $S$. aureus and MRSA. They found $23.7 \%$ S. aureus carriage among $10589 \mathrm{HCWs}$. In 127 investigations with denominator data, the average MRSA carriage was $4.6 \%$. Hawkins et al. ${ }^{15}$ from a literature review identified 18 papers published between April 2006 and March 2010 on carriage rates of HCWs ranging from $2 \%$ to $15 \%$. A systemic search for literature which conducted in MEDLINE and EMBASES databases was made by the authors, 31 studies were included in this review ${ }^{16}$. The MRSA colonization rate was $1.8 \%-4.4 \%$. The highest carriage rate was found in the nursing staff $(6.9 \%)$.

Kei et al. ${ }^{6}$ study 20 different inanimate objects in an ED and found only one MRSA from the ambulance bay security door keypad. Merlin et al. ${ }^{17}$ studied 50 stethoscopes for MRSA and found 32\%. Julian et al. ${ }^{18}$ sampled 123 mobile phones of veterinary teaching hospital staff. The MRSA was found $2.4 \%$ of the mobile phones. Roberts et al. ${ }^{19}$ found $21 \%$ dental students and $8.4 \%$ surfaces positive for MRSA.

In our study $S$. aureus/MRSA nasal carriage among ED workers $(18.1 \%, 2.9 \%)$ was not different from the similar studies especially from our country and studies from Europe, but studies from different countries out of Europe showed different and high carriage rates ${ }^{1-3,12-14}$. Nearly all the researchers say the same thing that HCWs have higher $S$. aureus/MRSA nasal carriage because of exposure ${ }^{1-3}$. HCWs are likely to be important in transmission of MRSA most frequently acting as vectors not as the main sources of MRSA transmission. Thus, good hand hygiene practices remain essential to control the spread of MRSA 5 .

In our hospital, the standard precautions on infection control policy, consistently highlighted with a booklet, prepared by infection control committee, which found all services and clinics and also brochures which highlighted the importance of hand washing. Also we think the studies about contamination and carriage with nosocomial pathogens raise the awareness in HCWs and must be followed up.

\section{Conflict of interest}

No conflict of interest.

\section{Financial support}

This study was supported by Erciyes University Scientific Research Project Unit.

\section{Reference}

1. Radhakrishna M, D'Souza M, Kotigadde S, Vishwas-Saralaya K, Shashidar-Kotian M. Prevalence of methicillin resistant Staphylococcus aureus carriage amongst health care workers of critical care units in Kasturba Medical College Hospital, Mangalore, India. Journal of Clinical and Diagnostic Research 2013;7(12): 2697-2700.

2. Shibabaw A, Abebe T, Mihret A. Nasal carriage rate of methicillin-resistant Staphylococcus aureus among Dessie Referral hospital health care workers; Dessie Northeast, Ethiopia. Antimicrobial Resistance and Infection Control 2013;2:25.

3. Iyer A, Kumosani T, Azhar E, Barbour E, Harakeh S. High incidence rate of methicillin-resistant Staphylococcus aureus among healthcare workers in Saudi Arabia. J Infect Dev Ctries 2014;8(3):372 PubMed -378.

4. Trepainer P, Tremblay C, Ruest A. Methicillin-resistant Staphylococcus aureus colonization among medical residents. Can J Infect Dis Med Microbiol 2013;24(2):e39-e41. 5. Albrich WC, Harbarth S. Health-care workers: soruce, vector, or victim of MRSA? Lancet Infect Dis 2008;8:289301 PubMed.

6. Kei J, Richards JR. The prevalence of methicillin-resistant Staphylococcus aureus on inanimate objects in an urban emergency department. The Journal of Emergency Medicine 2011;41(2):124-127.

7. Clinical Laboratory Standards Institute (2007) Performance standards for antimicrobial susceptibility testing, informational supplement, 17th ed.

8. Sufolletto BP, Canon EH, Ilkhanipour K, Yealy DM. Prevalence of Staphylococcus aureus nasal colonization in emergency department personnel. Annals of Emergency Medicine 2008;52(5):529-533.

9. Oguzkaya Artan M, Gulgun M, Baykan Z, Tok D. Investigation of nasal carriage rates and antimicrobial susceptibility of Staphylococcus aureus in hospital staff. Turkish J of Infection 2008;22(2):87-90.

10. Artan C, Oguzkaya Artan M, Baykan Z. Staphylococcus aureus nasal carriage among hospital staff and inducible clindamycin resistance. Düzce Üniversitesi Sağglk. Bilimleri Dergisi 2013;3(2):1 PubMed -4.

11. Naz H, Çevik FÇ, Aykın N. Nasal Staphylococcus aureus nasal carriage amonghospital staff in Eskişehir Yunus Emre State Hospital. ANKEM Derg 2006;20(3):141 PubMed -144 .

12. Elie-Turenne MC, Fernandes H, Mediavilla JR, Rosenthal M, Mathema B, Singh A, Cohen TR, Pawar KA, Shahidi H, Kreiswirth BN, Deitch EA. Prevalence and characteristics of Staphylococcus aureus colonization 
among healthcare professionals in an urban teaching hospital. Infection Control and Hospital Epidemiology 2010;31:574-580.

13. Askarian M, Zeinazadeh A, Japoni A, Alborzi a, Memish ZA. Prevalence of nasal carriage o methicillin resistance Staphylococccus aureus and its antibiotic susceptibility pattern in healthcare workers at Namazi Hospital, Shiraz, Iran. Int J Infect Dis 2009;13:e241-e247.

14. Mahalingam U, Thirunvukarasu T, Murugananthan K. Methicillin resistant Staphylococcus aureus among nurses in a tertiary care hospital in Sri Lanka. Ceylon Medical Journal 2014;59:63-65.

15. Hawkins G, Stewart S, Blachtford O, Reilly J. Should healthcare workers screened routinely for methicillin-resistant Staphylococcus aureus? A review of the evidence. J Hospital Infect 2011;77:285-289 PubMed .
16. Dulon M, Peters C, Schablon A, Nienhaus A. MRSA carriage among healthcare workers in non-outbreak settings in Europa and the United States: A systemic review. BMC Infect Dis 2014; 14:363.

17. Merlin MA, Wong ML, Rynn K, Margues-Baptista A, Perritt R, Stanescu CG, Fallon T. Prevalence of methicillin-reistant Stapbylococcus aureus on the stethoscopes of emergency department services providers. Prehospital Emergency Care 2009;13:71-74.

18. Julian T, Singh A, Rousseau J, Weese JS. Methicillin-resistant staphylococcal contamination of cellular phones of personnel in a veterinary teaching hospital. BMC Research Notes 2012;5:193.

19. Roberts MC, Soge OO, Horst JA, Ly KA, Milgrom P. Methicillin-resistant Staphylococcus aureus from dental school clinic surfaces and students. Am J Infect Control 2011:39:628-632 PubMed . 